\title{
Liquid Oxygen / Liquid Methane Test Results of the RS-18 Lunar Ascent Engine at Simulated Altitude Conditions at NASA White Sands Test Facility
}

\author{
John C. Melcher IV* \\ NASA Johnson Space Center, Houston, TX 77058 \\ Jennifer K. Allred ${ }^{\dagger}$ \\ NASA Johnson Space Center White Sands Test Facility, Las Cruces, NM 88012
}

\begin{abstract}
Tests were conducted with the RS-18 rocket engine using liquid oxygen $\left(\mathrm{LO}_{2}\right)$ and liquid methane $\left(\mathrm{LCH}_{4}\right)$ propellants under simulated altitude conditions at NASA Johnson Space Center White Sands Test Facility (WSTF). This project is part of NASA's Propulsion and Cryogenics Advanced Development (PCAD) project. "Green" propellants, such as $\mathrm{LO}_{2} / \mathrm{LCH}_{4}$, offer savings in both performance and safety over equivalently sized hypergolic propulsion systems in spacecraft applications such as ascent engines or service module engines. Altitude simulation was achieved using the WSTF Large Altitude Simulation System, which provided altitude conditions equivalent up to $\sim 122,000 \mathrm{ft}(\sim 37 \mathrm{~km})$. For specific impulse calculations, engine thrust and propellant mass flow rates were measured. $\mathrm{LO}_{2}$ flow ranged from $5.9-9.5 \mathrm{lbm} / \mathrm{sec}(2.7-4.3 \mathrm{~kg} / \mathrm{sec})$, and $\mathrm{LCH}_{4}$ flow varied from 3.0 - 4.4 $\mathrm{lbm} / \mathrm{sec}(1.4-2.0 \mathrm{~kg} / \mathrm{sec})$ during the RS-18 hot-fire test series. Propellant flow rate was measured using a coriolis mass-flow meter and compared with a serial turbine-style flow meter. Results showed a significant performance measurement difference during ignition startup due to two-phase flow effects. Subsequent cold-flow testing demonstrated that the propellant manifolds must be adequately flushed in order for the coriolis flow meters to give accurate data. The coriolis flow meters were later shown to provide accurate steady-state data, but the turbine flow meter data should be used in transient phases of operation. Thrust was measured using three load cells in parallel, which also provides the capability to calculate thrust vector alignment. Ignition was demonstrated using a gaseous oxygen/methane spark torch igniter. Test objectives for the RS-18 project are 1) conduct a shakedown of the test stand for $\mathrm{LO}_{2}$ /methane lunar ascent engines, 2) obtain vacuum ignition data for the torch and pyrotechnic igniters, and 3) obtain nozzle kinetics data to anchor two-dimensional kinetics codes. All of these objectives were met with the RS-18 data and additional testing data from subsequent $\mathrm{LO}_{2}$ /methane test programs in 2009 which included the first simulated-altitude pyrotechnic ignition demonstration of $\mathrm{LO}_{2} /$ methane.
\end{abstract}

\section{Introduction}

The 2005 NASA Exploration Systems Architecture Study (ESAS) recommended that the crew exploration vehicle (CEV) lunar surface access module (LSAM) ascent stage propulsion and service module propulsion systems employ a pressure-fed $\mathrm{LO}_{2}$ /methane technology. ${ }^{1}$ The mass savings over monomethyl hydrazine (MMH) / and nitrogen tetroxide (NTO) were around $1,000-2,000 \mathrm{lbm}(450-910 \mathrm{~kg})$ for the LSAM ascent module, which was larger than the current design. The thrust levels identified in ESAS were 5,000 - 10,000 lbf $(22-44 \mathrm{kN})$ for the ascent engine. To remove key technology risks in the decision for hypergolic or $\mathrm{LO}_{2} /$ methane, the Propulsion and Cryogenics Advanced Development (PCAD) project is being conducted within NASA, led by the Glenn Research Center, for $5,500 \mathrm{lbf}(24,500 \mathrm{~N})$ ascent engine technology.

\footnotetext{
*Aerospace Engineer - Liquid Propulsion Systems, Energy Systems Division, EP4, AIAA Senior Member

${ }^{\dagger}$ Project Manager; NASA White Sands Test Facility Propulsion Test Office, RD, AIAA Member
} 
Another reason to pursue the development of $\mathrm{LO}_{2}$ /methane propulsion systems is the potential for in-situ resource utilization during Mars and lunar missions. Oxygen should be able to be harvested from the lunar regolith and Martian soil and ice, and methane can be obtained from the Martian atmosphere. ${ }^{2}$ In-situ propellant generation reduces vehicle mass requirements to the surface. Early development of $\mathrm{LO}_{2} /$ methane propulsion systems prior to Mars missions provides technology maturity. Lastly, an $\mathrm{LO}_{2}$-based propulsion system provides fluid commonality with power and life support systems, which also may utilize in-situ resource technology.

For future human spaceflight vehicles, $\mathrm{LO}_{2} / \mathrm{LCH}_{4}$ propulsion systems offer benefits in safety and performance compared to hypergolic propellants. For example, the hypergolic propellants, $\mathrm{MMH} / \mathrm{NTO}$, which have been used in the United States human space program propulsion systems, are known toxic substances. MMH and NTO not only introduce ground handling safety risk and process complexity, they also introduce risks to the crew. In addition to the propellants being non-toxic, the $\mathrm{LO}_{2}$ /methane combustion process also provides "cleaner" combustion products $\left(\mathrm{CO}, \mathrm{CO}_{2} \text {, and } \mathrm{H}_{2} \mathrm{O}\right)^{3}$ as compared to hypergolic propellants combustion products.

To initiate lunar ascent engine testing, PCAD arranged a Space Act Agreement with Pratt and Whitney Rocketdyne to test an RS-18 engine using $\mathrm{LO}_{2}$ /methane. The RS-18 engine was used as the Apollo Lunar Excursion Module (LEM) ascent engine, and it operated on NTO/Aerozine-50 (a 50/50 blend of Hydrazine and Unsymmetrical Dimethylhydrazine, UDMH). Operating on NTO / Aerozine-50, the RS-18 provided $\sim 3,500 \mathrm{lbf}(\sim 15.6 \mathrm{kN})$ thrust at $\sim 310 \mathrm{sec}$ specific impulse and 1.6 mixture ratio. ${ }^{4}$ In the Apollo LEM Ascent Propulsion System, oxidizer flow rates were $\sim 7 \mathrm{lbm} / \mathrm{sec}(\sim 3 \mathrm{~kg} / \mathrm{sec})$ and fuel flow rates were $\sim 4 \mathrm{lbm} / \mathrm{sec}(1.8 \mathrm{~kg} / \mathrm{sec}) .{ }^{4}$ Figure 1 shows the ascent stage of the Apollo LEM during Apollo missions 11 and 9. Although the RS-18 would be operating less than optimally on $\mathrm{LO}_{2} /$ methane, the engine was chosen as a pathfinder test engine that would provide a design point for buildup and testing of a lunar ascent engine test stand. Flow rate measurement and thrust measurement were sized so that future scaling of the test stand would be minimal and common controls, sensors, and instrumentation could be maintained for future test projects.
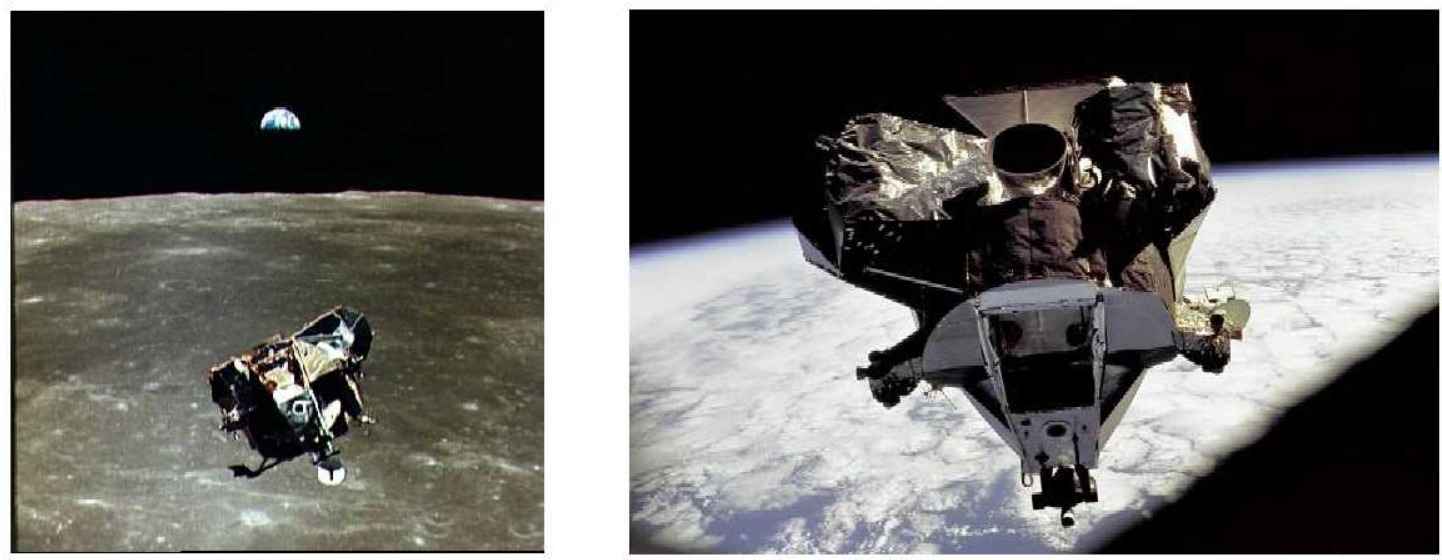

Figure 1: (a) Apollo 11 Lunar Module ascent stage, with the Earth rising about the lunar horizon, and (b) Apollo 9 Lunar Module in Earth orbit before rendezvous.

\section{RS-18 Testing in WSTF Test Stand 401}

For simulated altitude conditions ground testing, the White Sands Test Facility (WSTF) Test Stand (TS) TS-401 was chosen. White Sands' TS-401 was originally developed to support the Apollo LEM integrated ascent and descent propulsion systems tests in 1964. The Large Altitude Simulation System (LASS), integral to TS-401, was capable of achieving simulated altitude conditions of $\sim 122,000 \mathrm{ft}(\sim 37 \mathrm{~km})$ altitude at the RS-18 thrust and mass flow rates. The LASS uses steam ejection in a diffuser to create simulated altitude conditions. The LASS TS401 and the steam ejector for the LASS are shown in Figure 2. A test bed rig that has been developed for use in TS401 is the Auxiliary Propulsion Systems Test Bed (APSTB), shown in Figure 3. The APSTB was originally designed and built to support the Space Shuttle non-toxic reaction control system upgrades project, and it provides a near stand-alone test platform with both fuel and oxidizer tankage with 550 gal $(2100 \mathrm{l})$ run tanks, manifolds, thrust measurement, and flow-rate measurement. Most recently, the APSTB was configured to support preceding "green" propellant projects, utilizing $870 \mathrm{lbf}(3.9 \mathrm{kN})$ thrust reaction control engine (RCE) applications for $\mathrm{LO}_{2} /$ ethanol $(2005-2006)^{5,6}$ and $\mathrm{LO}_{2} /$ methane (2006-2007). ${ }^{7}$ Specific modifications to the APSTB for RS-18 are described in Ref. 8 . 
The APSTB was designated to support two tests concurrently, both the $\mathrm{LO}_{2} /$ methane RS-18 and a $\mathrm{LO}_{2} /$ methane RCE for prospective Altair applications. The overall layout of the APSTB modifications was such that the RS-18 was aligned vertically and centered on the APSTB truss so that the nozzle exhaust could be ducted directly into the TS-401 LASS diffuser inlet. Figure 3 shows the overall design layout of the new $\mathrm{LO}_{2} /$ methane engines mounted on the APSTB and installed in TS-401. Figure 4 shows the RS-18 installed on the APSTB in TS401. Figure 5 shows the RS-18 propellant manifold and thrust measurement system overall layout.

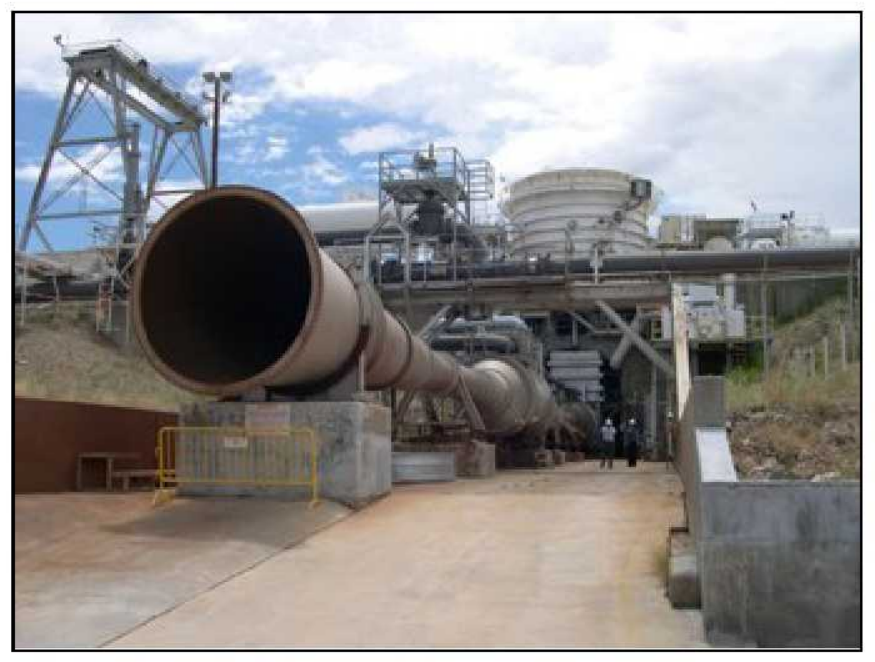

Figure 2: WSTF TS-401 with LASS ejector exhaust shown.
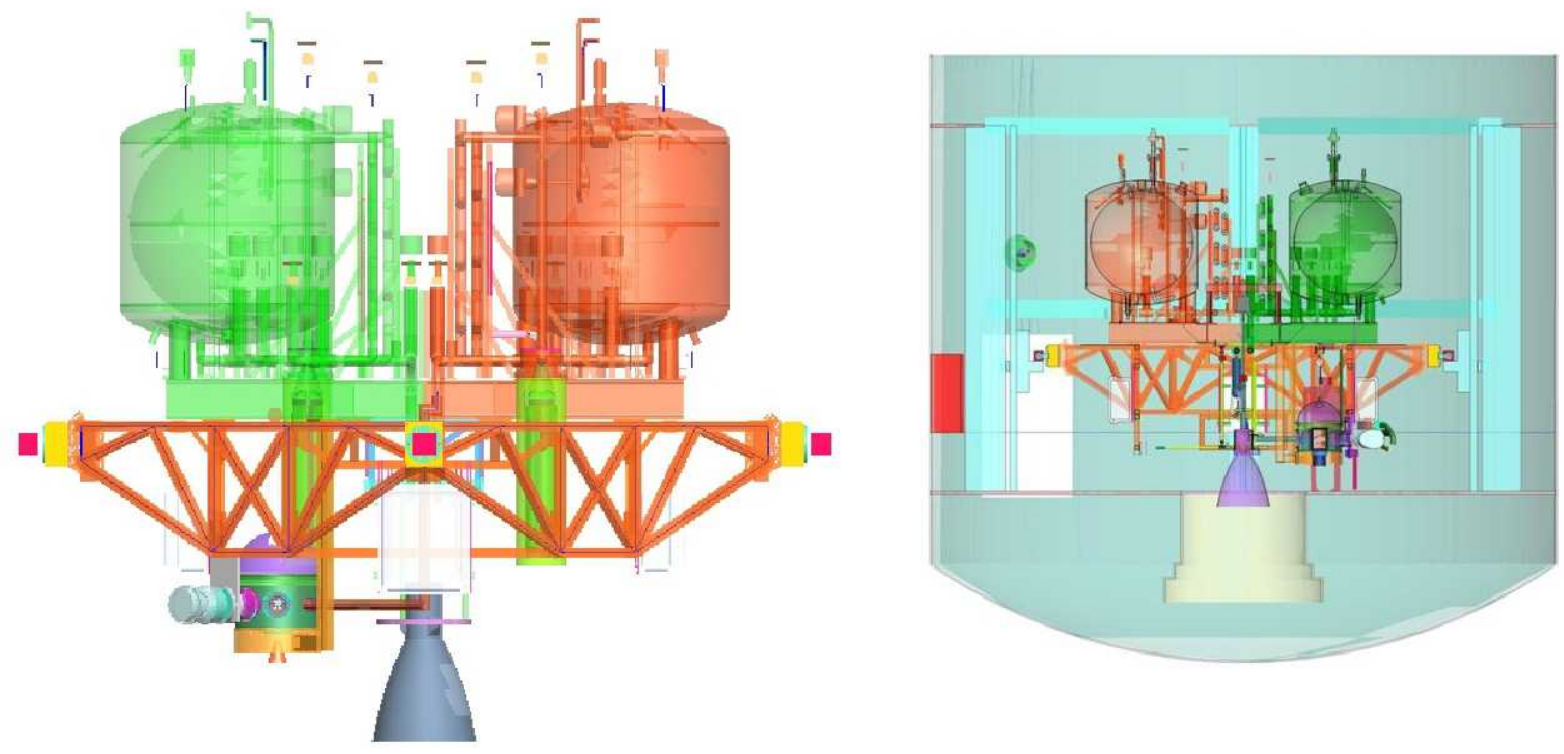

Figure 3: (a) APSTB shown with RS-18 mounted. (b) APSTB installed in TS-401. 


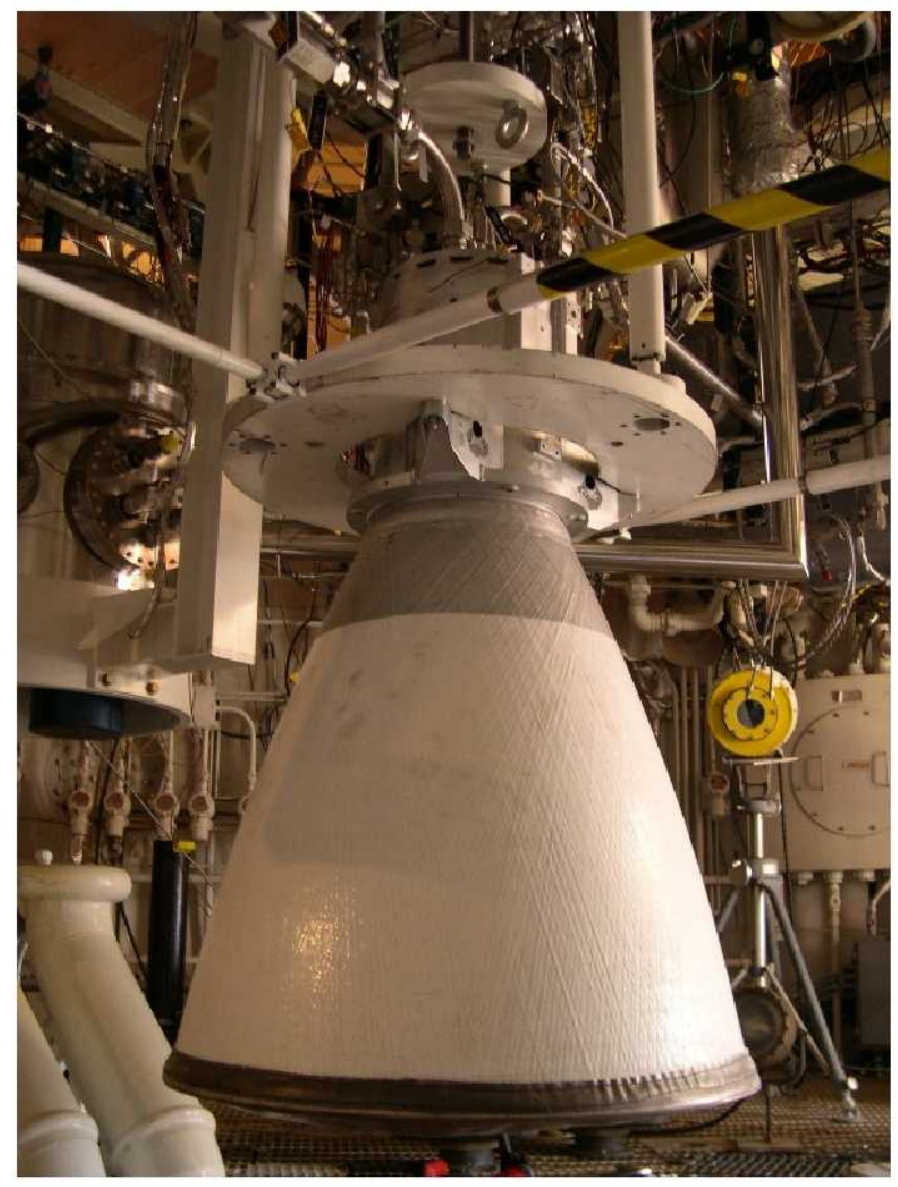

Figure 4: RS-18 Installed on APSTB mounted in WSTF TS-401.

For the RS-18 test series, the capability to perform two different ignition methods was added to TS-401, gaseous spark-torch igniter supply and pyrotechnic igniter. The design configuration allows for three igniters to be operated simultaneously if required. This capability also allows demonstration of dual diverse igniters if desired (e.g., simultaneous redundant gas torch and pyro igniter firing). The RS-18 gas spark-torch igniters were designed and supplied by Pratt and Whitney Rocketdyne as part of the $\mathrm{LO}_{2} /$ methane RS- 18 test program, and TS-401 provides the gaseous oxygen $\left(\mathrm{GO}_{2}\right)$ and gaseous methane $\left(\mathrm{GCH}_{4}\right)$ directly to the torch igniters.

Three tests successfully demonstrated vacuum ignition of the RS-18, shown in Figure 6. The tests were conducted for durations less than $1 \mathrm{sec}$ due to temperature constraints of the engine hardware. Simulated altitude conditions ranged from 103,000 - 122,000 ft $(31-37 \mathrm{~km})$. Extended test durations were not performed due to TS401 availability constraints. Even though the tests were limited to less than $1 \mathrm{sec}$ duration, approximately $0.5 \mathrm{sec}$ of steady-state run-time measurements was made during each test. Thrust and mass flow measurements were made and specific impulse and $\mathrm{C}^{*}$ efficiency were calculated for each test.

\section{Thrust Measurement}

Thrust and propellant mass flow rates must be accurately measured to minimize error stack up in the calculation of specific impulse. To accomplish the thrust measurement accurately, a three column load-cell arrangement was utilized. This design was based on the configuration used during the Apollo LEM descent main engine testing. Figure 5 shows the arrangement of the three load columns. The three-column arrangement minimizes error from off-axis thrust loads and assists in alignment when tested with the load calibration air cylinder. Each load column includes one Tovey Engineering Inc. load cell (Model SWP10) dual-bridge, shear web precision series force transducer, rated for 2,000 $\mathrm{lbf}(8,900 \mathrm{~N})$. The vendor-provided accuracy of the transducers is 0.02 $0.04 \%$ static error band at full scale. 


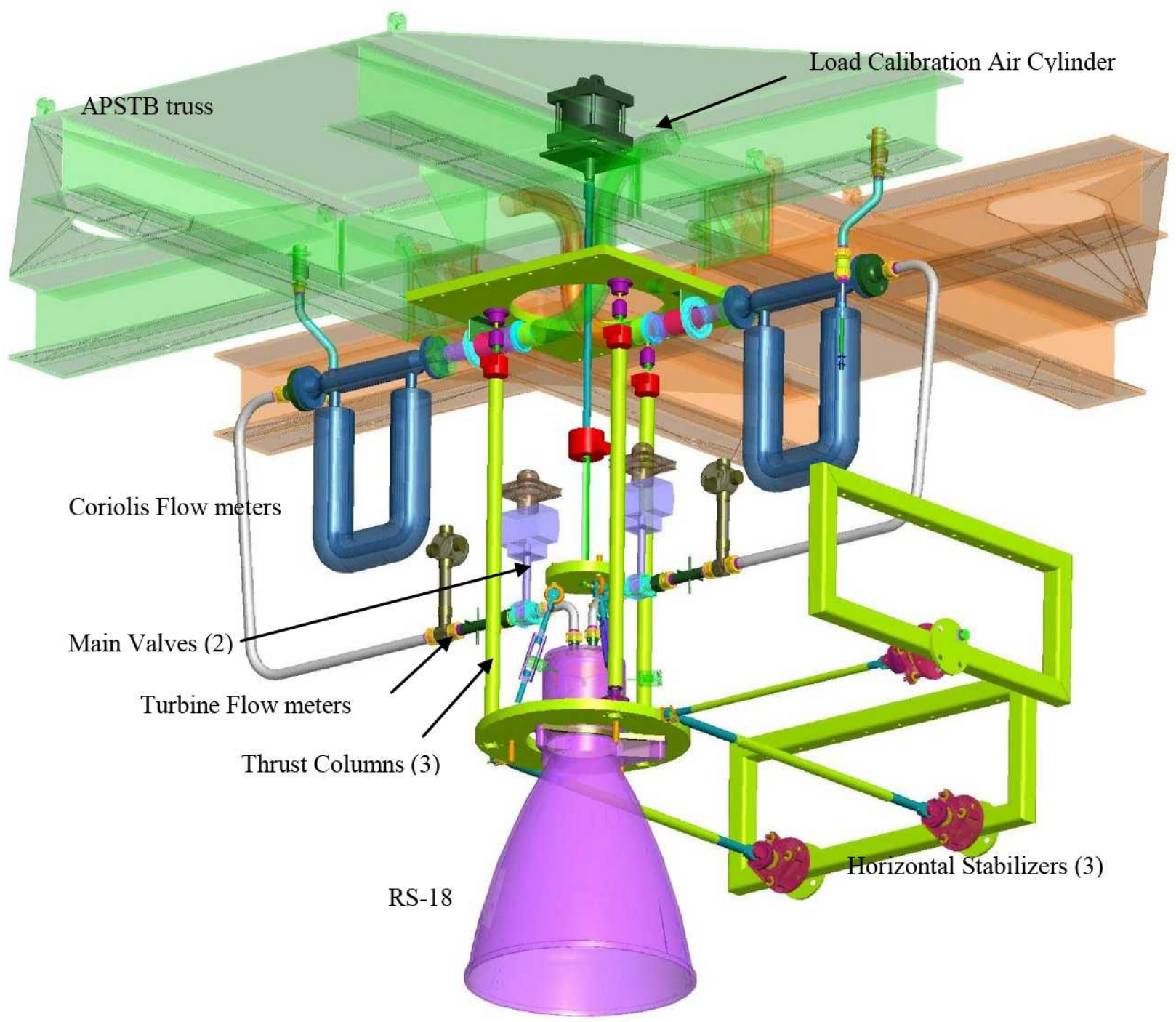

Figure 5: Major components of theRS-18 test apparatus installed on the APSTB.

For thrust measurement calibration, the engine thrust structure has secondary attachments to a centered load calibration air cylinder (shown in Figure 5). When the air cylinder applies tensile load to the engine mounting (i.e., the air cylinder pulls up on the engine mount), a simulated thrust load is applied to the three thrust measurement columns. A single 10,000 lbf (44.4 kN) Tovey Engineering Inc. load cell is included in the thrust calibration mechanism so that the applied tensile load is also measured. The calibration data is used in a one-dimensional static load analysis that is performed in two parts, as shown in Figure 7. First, the known calibration load, FCAL, from the air cylinder is used to calculate an equivalent system resistive force, FRESIS, which increases as the applied load increases. In other words, the resistive force is the calculated difference between the known applied air cylinder force and the measured force of the three columns, FMEASi, when in calibration. This resistive force is due largely to propellant manifold loads. Second, the calculated resistive force curve is then added to the measured thrust during test to determine the actual thrust from the engine. In both the calibration and hot-fire measurements, the pre-test thrust off-set, FWEIGHT, is zeroed out. Key assumptions in this methodology are that the system is onedimensional in the direction of the thrust and that steady-state analysis can be performed as a static model. 


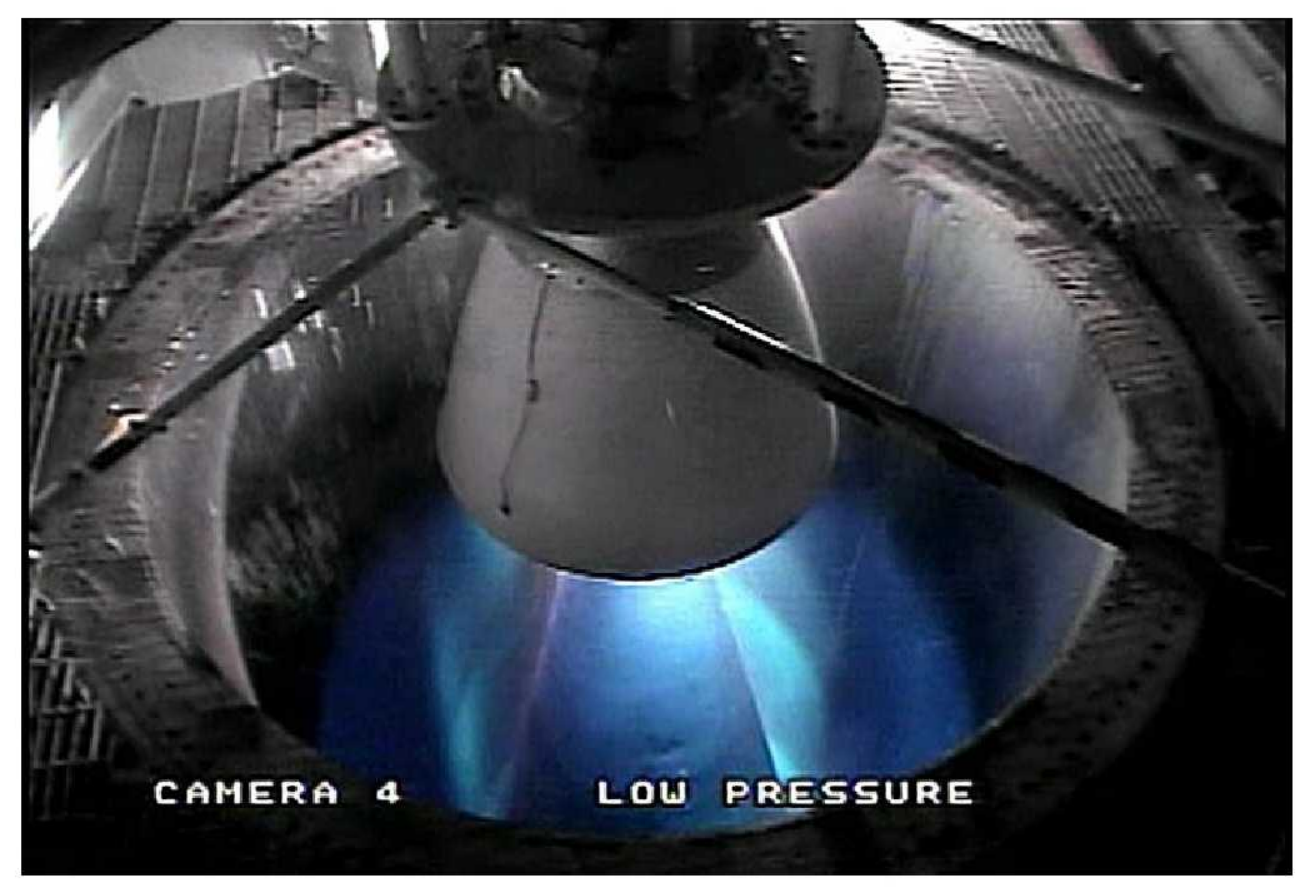

Figure 6: Hot-fire test imagery of RS-18 vacuum ignition demonstration test.

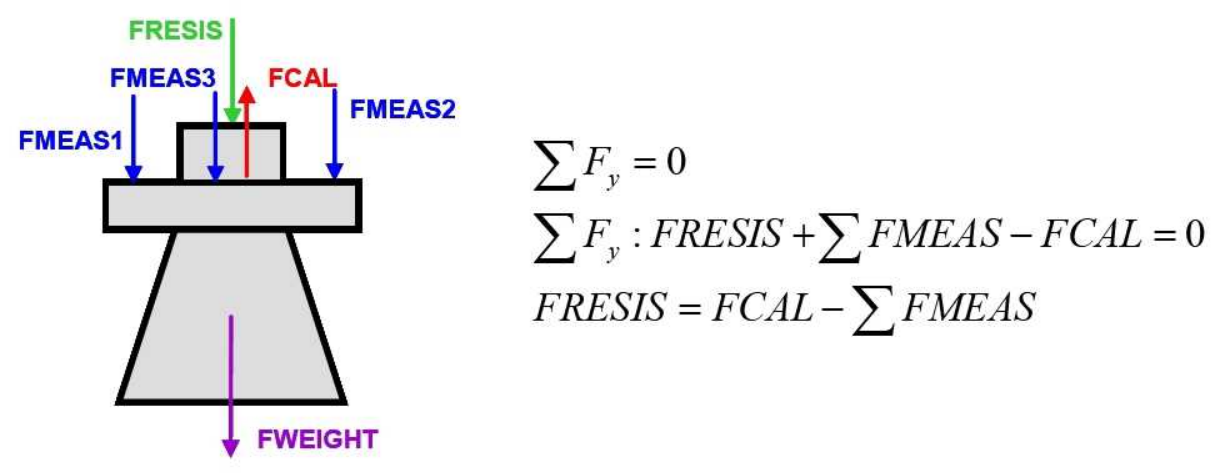

Figure 7: Free-body diagram and static-load analysis for thrust calibration, note that pretest thrust offset, FWEIGHT, is zeroed out in the analysis.

Additional thrust stand characterization was performed to determine the natural frequency response of the APSTB and RS-18 manifolds. Filtering the natural frequency stand response from the thrust data will improve the thrust measurement accuracy. As shown in Figure 8, the response time from valve opening command to $90 \%$ full thrust is $\sim 0.28 \mathrm{sec}$, which was repeatable in all hot-fire tests, ranging $\sim 0.25-0.28 \mathrm{sec}$. As reported in Ref. 8 , the $1.25 \mathrm{inch}(3.2 \mathrm{~cm}) \mathrm{LO}_{2}$ valve timing was set to $\sim 100 \mathrm{msec}$ for the RS-18 tests. 


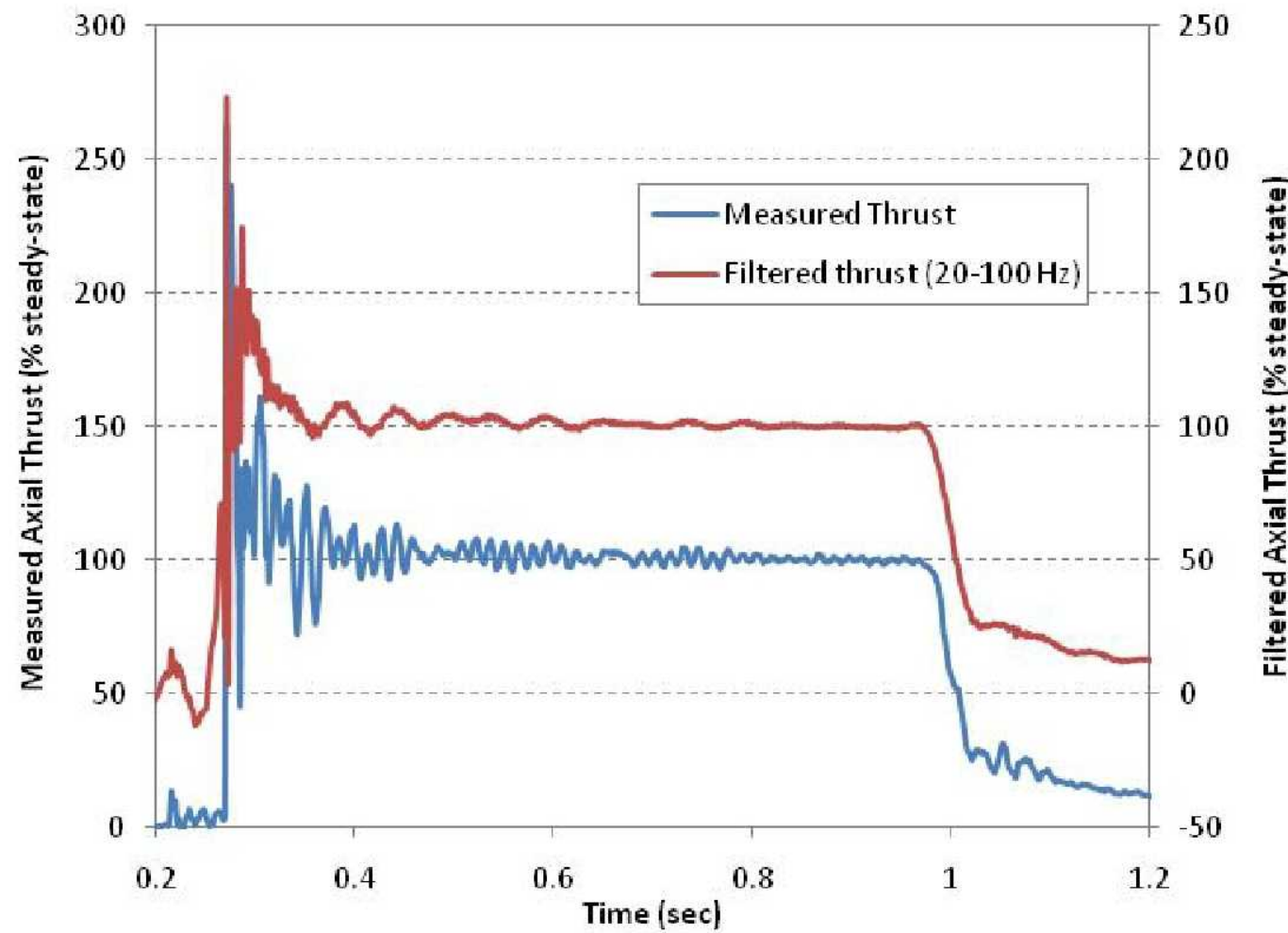

Figure 8: Example non-dimensionalized thrust output from RS-18 test. Delay from valve open command to $90 \%$ thrust is $\sim 0.28 \mathrm{sec}$. Measured data and filtered (20-100 Hz notch filter) data shown.

Impact hammer tests showed a strong $60 \mathrm{~Hz}$ noise, either mechanical or electrical. As shown in Figure 8, significant noise reduction was obtained post-processing by introducing a notch filter centered at $60 \mathrm{~Hz}$ with bandwidths up to $+/-40 \mathrm{~Hz}$ in order to remove the low-frequency ringing signature. By applying a $20-100 \mathrm{~Hz}$ notch filter to the data, the scatter could be reduced by half (e.g., $2.6 \% 3$-sigma scatter without notch filter, $1.3 \% 3$ sigma scatter with notch filter applied) after the initial large-scale oscillations dampen.

Lastly, the use of three load cells in parallel provides the capability to calculate the thrust vector alignment of the RS-18 in test. Similar to the total thrust calibration described above, a two-step static load analysis was performed on the system. First, the equivalent resistive forces, FRESISi, were calculated at three arbitrary points on the thrust structure, chosen at the three attach points of the feet of the RS-18, shown in Figure 9. Note that similar to the overall measurement analysis, the pre-test offset is zeroed out in the analysis. A key assumption in the analysis is that the calibration air cylinder load is transferred to the thrust structure equally in three places, i.e., $F C A L i=1 / 3$ FCAL. As shown in Figure 4, the calibration load is translated to the thrust ring through three turnbuckles, which are measured to be equal length. As described above, the three components of the resistance force, FRESISi, are applied to the measured load, $F M E A S i$, in a static analysis for hot-fire test to calculate the applied load at the three attach points of the RS-18 to the thrust ring. Therefore, the total equivalent thrust and its $\mathrm{x}, \mathrm{y}$ coordinate can be calculated. Figure 10 shows an example output calculation of the thrust vector alignment during the steady-state window of a test (i.e., start and shutdown transients not shown). Note that the vector does not focus on centerline, but lies within a 0.5 in $(1.25 \mathrm{~cm})$ of center. 


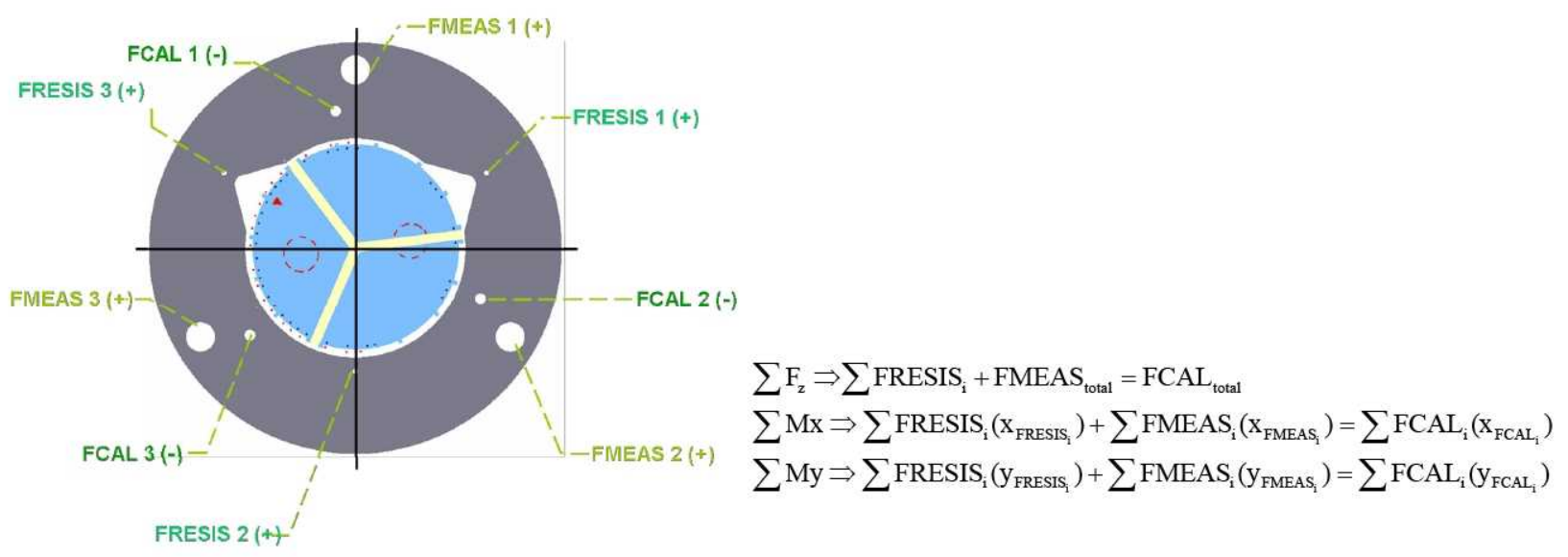

Figure 9: Free-body diagram and static load analysis for thrust calibration used in thrust vector alignment calculation. Note that pre-test thrust offset is zeroed out in the analysis.

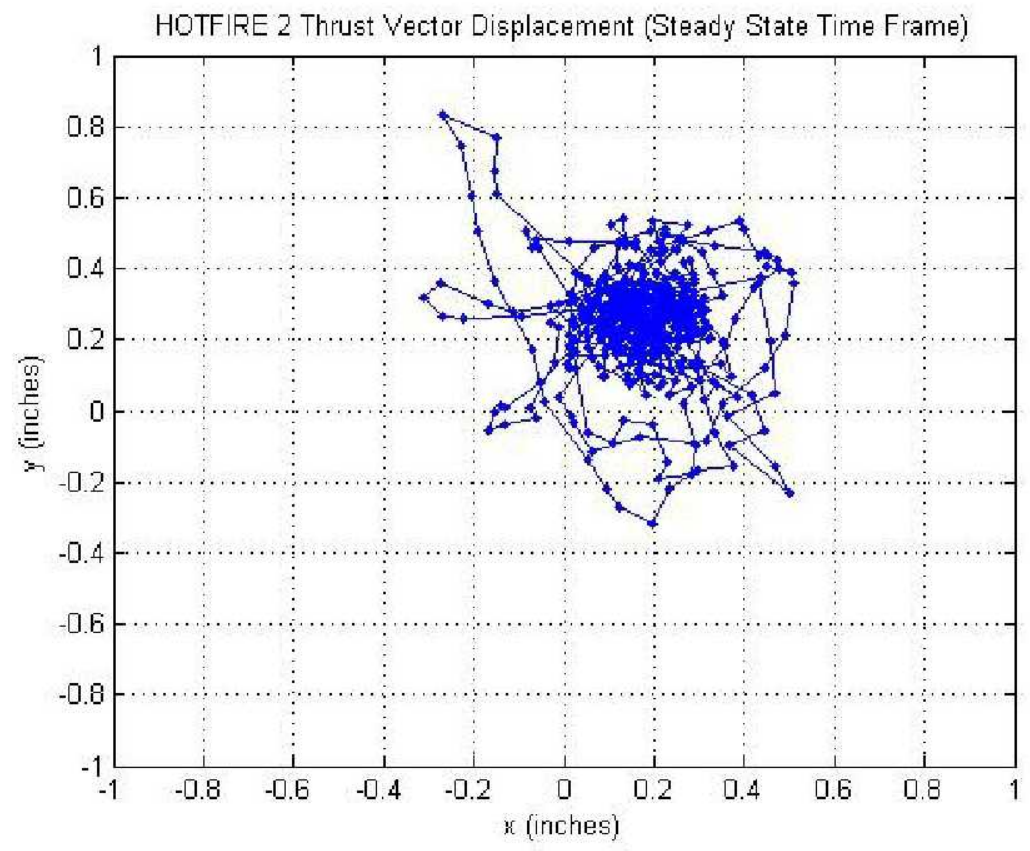

Figure 10: Example output calculation of thrust vector center from hotfire test steady-state.

\section{Propellant Flow Rate Measurement}

For propellant flow rate measurement, a redundant series approach was adopted using both a coriolis massflow meter and a turbine flowmeter, shown in Figure 5. The coriolis mass flow meters are Micro Motion, Elite model CMF200M, 2 inch diameter. For cryogenic operations, the micro-motion coriolis flow meter includes a skin temperature transducer to automatically correct for metal bending factors. The vendor-reported accuracy at the cryogenic conditions is $0.05 \%$, but a National Institute of Standards and Technology (NIST) study report shows $0.25 \%$ accuracy for a similar model and flow rate. ${ }^{9}$ Reports and anecdotal evidence suggest the greatest problems for coriolis flowmeter accuracy resulted from propulsion tests with short run times (e.g., run times less than 500 $\mathrm{msec}$ ) ${ }^{10}$ Additional points of concern raised were the performance of the coriolis meters in a vibration environment or in two-phase flow. As will be shown later, it is evident in the quality of the flow meter signal that the vibration concerns had been adequately mitigated for steady-state analysis.

American Institute of Aeronautics and Astronautics 
For comparison to the coriolis meters, each propellant manifold includes a turbine flowmeter downstream of the coriolis flow meters, upstream of the bleed manifolds. The turbine meters are Hoffer Flow Controls, Inc., 1.5 inch $(3.8 \mathrm{~cm})$ diameter, model HO liquid flow meters, and the accuracy provided by the vendor is $0.5 \%$. For mass-flow calculations from the turbine flowmeter data, the temperature and pressure measured at the propellant bleed manifolds are used. The bleed measurements are located downstream of the turbine flowmeters, but upstream of the main valves, shown in Figure 5. Density is then calculated using the REFPROP executable or Excel spreadsheet macros. ${ }^{11}$ For the density calculations, it is assumed that the fluid is a pure liquid (i.e., no two-phase flow). The vendor-supplied error for REFPROP density is $0.1 \%$ for $\mathrm{LO}_{2}$ and $0.03 \%$ for $\mathrm{LCH}_{4} . \mathrm{LO}_{2}$ steady-state flow rates ranged from $5.9-9.5 \mathrm{lbm} / \mathrm{sec}(2.7-4.3 \mathrm{~kg} / \mathrm{sec})$, and $\mathrm{LCH}_{4}$ flow varied from $3.0-4.4 \mathrm{lbm} / \mathrm{sec}(1.4$ $2.0 \mathrm{~kg} / \mathrm{sec}$ ) during the RS-18 hot-fire test series.

Test results show that the coriolis flowmeters' performance experienced a significant startup transient compared to the turbine flowmeter data. Figure 11 shows the $\mathrm{LO}_{2}$ turbine and coriolis flow meter output during a 0.7 sec duration ignition demonstration test. The turbine flowmeter data has been converted to mass flow meter data using REFPROP. The $\mathrm{LO}_{2}$ coriolis flowmeter eventually matches the turbine flowmeter steady-state output after $\sim 0.5 \mathrm{sec}$ delay, and the $\mathrm{LCH}_{4}$ coriolis flowmeter never reaches the steady-state value during the short test duration. It is believed that the coriolis flowmeter response delay is only a transient affect at startup due to two-phase flow transients. The hypothesis is that gas pockets and bubbles that form in the propellant manifolds must be adequately flushed from the system before the flow meters provide a functional response.

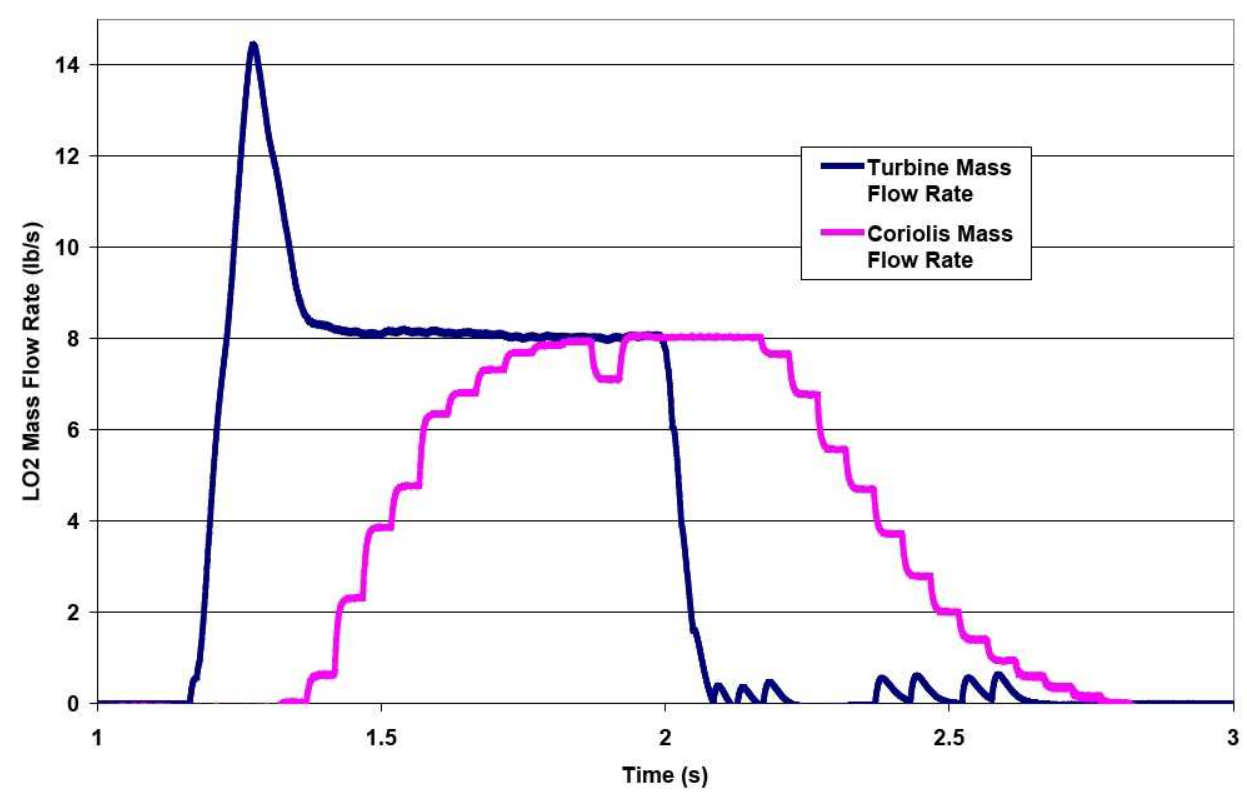

Figure 11: $\mathrm{LO}_{2}$ Turbine flow meter comparison with coriolis flow meter data for ignition demonstration $0.7 \mathrm{sec}$ duration test of the RS-18 engine.

Additional cold-flow testing was conducted in April 2009 as part of a $\mathrm{LO}_{2} /$ methane engine test program conducted as an Innovative Partnership Program (IPP) with Armadillo Aerospace. During those cold flows, the two-phase flow problem was proven to be the cause of the poor quality coriolis flow meter data recorded during RS18. Data shows that for a given test day, coriolis flow meter performance improves with test duration during successive tests on a single test day. For example, as shown in Figure 12, the $\mathrm{LO}_{2}$ coriolis flow meter response for the first and second tests on a single day were unresponsive or sluggish, similar to the RS-18 test data. However, by the third and fourth cold-flow tests, the data had become responsive and accurate. Note that this trend was only observed on the $\mathrm{LO}_{2}$ flow meter; the $\mathrm{LCH}_{4}$ flow meter cold flow tests were conducted with liquid nitrogen $\left(\mathrm{LN}_{2}\right)$. The $\mathrm{LCH}_{4}$ flow meter was not rated to function at $\mathrm{LN}_{2}$ temperatures, and output was non-functional under $\mathrm{LN}_{2}$ temperature conditions. 


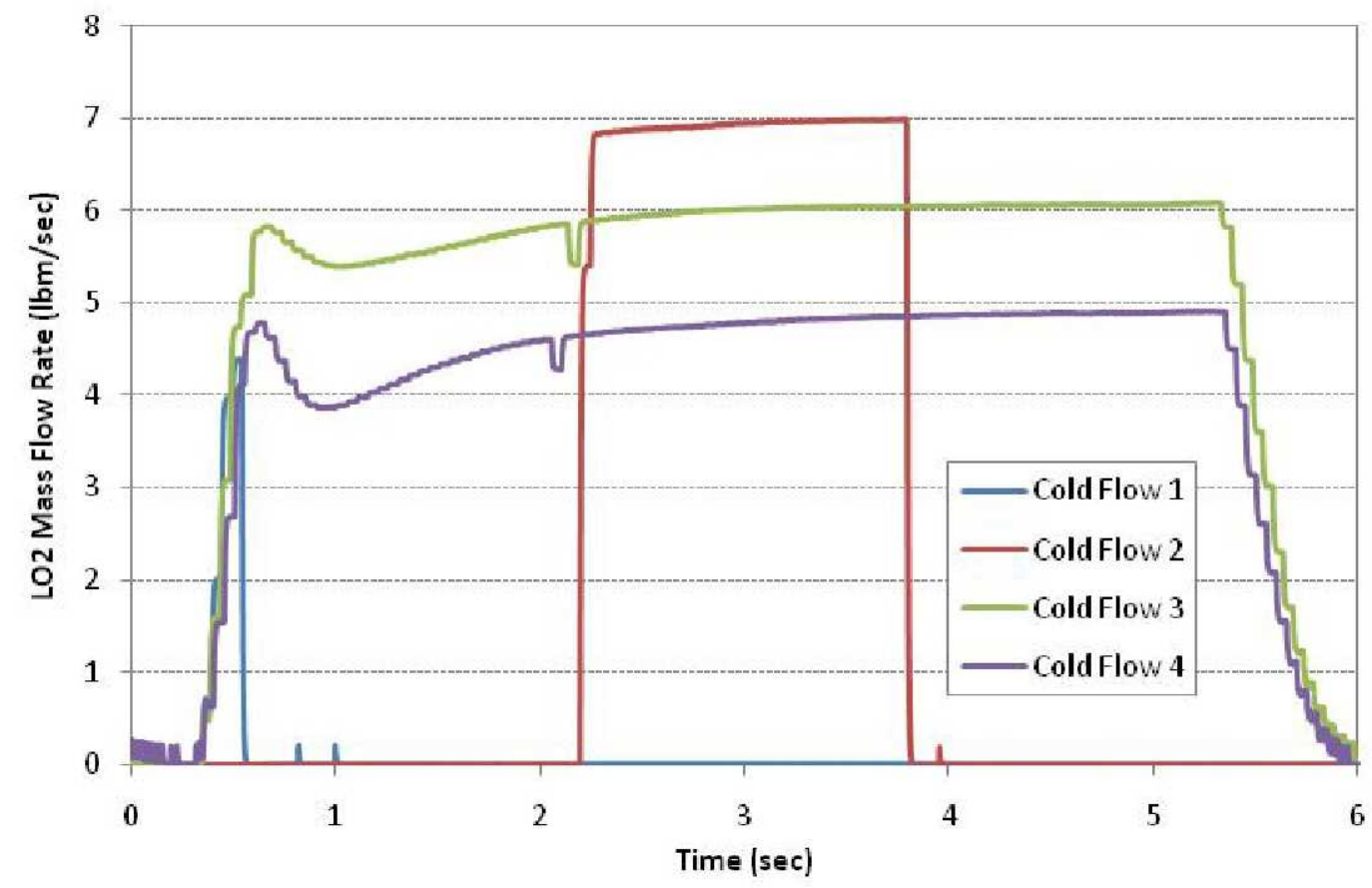

Figure 12: $\mathrm{LO}_{2}$ coriolis flow meter cold-flow data for four successive tests conducted during a single test day during Armadillo Aerospace IPP engine testing.

A second piece of evidence of the two-phase flow effect was observed during hot-fire testing of the Armadillo Aerospace engine. Hot-fire tests were conducted on the Armadillo Aerospace engine without any pre-test cold-flows or manifold flushing. In these hot-fire tests, both the $\mathrm{LO}_{2}$ and $\mathrm{LCH}_{4}$ coriolis flow meters did not respond until approximately 10-12 sec into the test, at which point the flow meter performance became fully functional and accurate (see Figure 13). This 10-12 sec is approximately the same amount of cumulative cold-flow testing that was required to flush the propellant manifolds during cold-flow operations before the coriolis flow meters would become operational.

As shown in the Armadillo Aerospace hot-fire test data, the data scatter of the measured $\mathrm{lbm} / \mathrm{sec}$ of the coriolis flow meter was $0.2-0.3 \%$ 1-sigma. In comparison, the data scatter in the turbine flow meter was $0.6-0.7$ $\%$ 1-sigma. The function of the coriolis flow meters demonstrate that they can be a useful tool for measuring steady-state mass flow in cryogenic propellant rocket engine testing. However, because of the response of the coriolis flow meter data and accuracy through engine startup transients, an additional flow meter (e.g., a turbine flow meter) should be designed in series to provide more accurate transient data. Additionally coriolis flow meter performance could be improved by flushing or cold-flow of the propellants for $\sim 10 \mathrm{sec}$ during operations prior to the engine hot-fire test.

\section{Conclusions and Forward Work}

Test objectives for the RS-18 project are 1) conduct a shakedown of the test stand for $\mathrm{LO}_{2} /$ methane lunar ascent engines, 2) obtain vacuum ignition data for the torch and pyrotechnic igniters, and 3) obtain nozzle kinetics data to anchor two-dimensional kinetics codes. Objective 1 was met by obtaining thrust and flow measurement data. Thrust measurement was demonstrated, and it was discovered that thrust measurement data requires post-processing filtering to remove electrical and mechanical noise. Mass flow measurement was achieved using two separate methods. Objective 2 was demonstrated with vacuum ignition of the main engine with the gas torch igniter, and the pyrotechnic vacuum ignition was demonstrated as part of the 2009 Armadillo Aerospace IPP engine testing (see below). Lastly, Objective 3 was met by the measured performance data now being analyzed for kinetics modeling (e.g., TDK modeling), which is part of the ongoing forward work. 


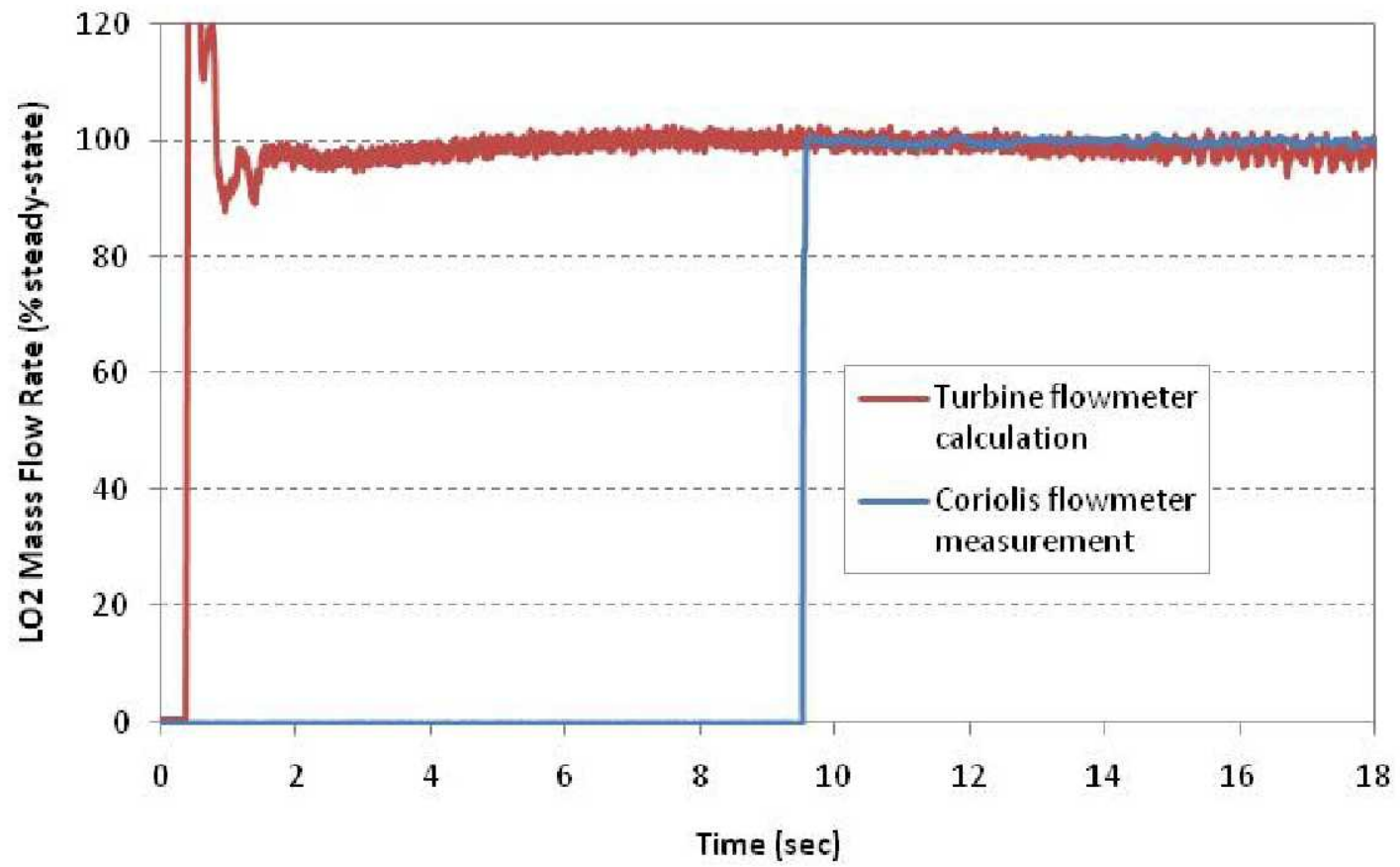

Figure 13: $\mathrm{LO}_{2}$ coriolis flow meter and turbine flow meter data from hot-fire during Armadillo Aerospace IPP engine testing (data shown as \% lbm/sec steady-state). Turbine flow meter data measured in gpm, density calculated from REFPROP.

Additionally, a recommendation has been provided for the use of coriolis flow meters for mass flow measurement in cryogenic propellant rocket engine test applications. The coriolis flow meters provide accurate data after transient two-phase flow effects are flushed from the system. An additional flow meter (e.g., turbine flow meter) should be used in series for transient phases of operation. Lastly, pre-test flushing or cold-flow of the propellant manifolds should provide improved coriolis flow meter response.

Due to time constraints, pyrotechnic ignition was not attempted on the RS-18, but was subsequently successfully demonstrated as part of the 2009 Armadillo Aerospace IPP engine testing. In 2008, J2-X Gas Generator pyrotechnic igniters were procured from Pacific Scientific for the use in RS- $18 \mathrm{LO}_{2} /$ Methane main engine testing. As shown in Figure 14, bench-top level mock-up tests were conducted at JSC Energy Systems Test Area in November 2008 in order to verify the RS-18 injector was materially and thermally compatible with the J2-X igniter, but a continuation of RS-18 testing was deferred. Pyrotechnic ignition of a $\mathrm{LO}_{2} /$ Methane main engine was added to the Armadillo Aerospace IPP. In February 2009, the J2-X pyro successfully ignited the Armadillo Aerospace engine at sea - level Armadillo Aerospace test facilities. $\mathrm{LO}_{2} / \mathrm{Methane}$ main engine vacuum pyro ignition was demonstrated at WSTF TS-401 in April 2009.

\section{Acknowledgements}

The PCAD project managers at Glenn Research Center are Tim Smith and Mark Klem. The PCAD technical officers at Johnson Space Center are Kris Romig and Eric Hurlbert. WSTF engineering support was executed by Jim Mahoney, Alton Luper, Helm Zander, Erin Edgerly, Joel Fountain, Aaron Hobson, Mike Owen, Jim Hansen, and Jeremy Bruggemann. JSC engineering and design support was provided by Mike Cabiran, Victor Spencer, Jacob Collins, Rich Schoenberg, and Rafael Jimenez. The Pratt and Whitney Rocketdyne team supporting the RS-18 activity include Terry Lorier, Alfred Little, Andrew Ketchum, Mark Horn, Tom Martin, and Fred Dodd. Dynamic pressure model analysis was conducted by Don Varanauski of the Boeing Company. Additional support was provided from the Marshall Spaceflight Center by Huu Trinh, Joel Robinson, and David Stephenson. J2-X Gas Generator Pyrotechnic Igniter support was provided by Ralph Hsiao and David Giles of Pacific Scientific Energetic Materials. Data reduction and analysis was performed at JSC by Stephanie Sumcad, Ian Meginnis, and Riana Ignacio. Armadillo Aerospace engineering support was provided by Phil Eaton. 


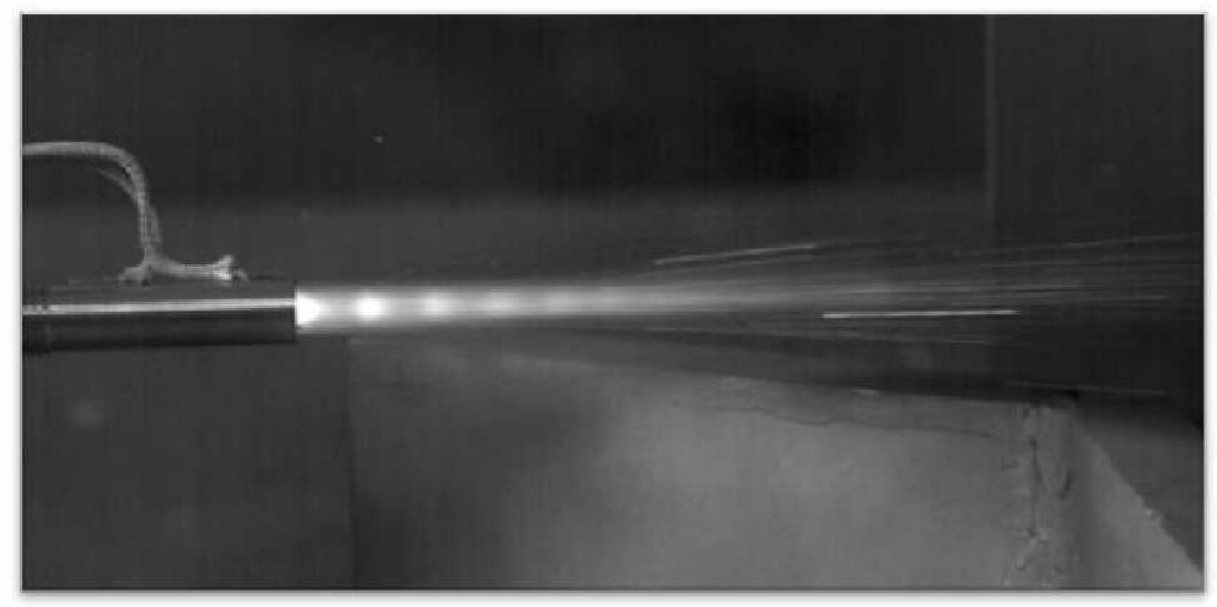

Figure 14: RS-18 configuration bench-level testing of the J2-X Gas Generator pyrotechnic igniter.

\section{Nomenclature}

\begin{tabular}{|c|c|}
\hline APSTB & Auxiliary Propulsion Systems Test Bed \\
\hline ESAS & Exploration Systems Architecture Study \\
\hline ESTA & Energy Systems Test Area \\
\hline FCALi & Thrust Stand Calibration load, $\mathrm{i}=1,2,3, \operatorname{lbf}(\mathrm{kN})$ \\
\hline FMEASi & Thrust Stand Measurement, i=1,2,3, lbf (kN) \\
\hline FRESISi & Thrust Stand Resistance, i=1,2,3, lbf (kN) \\
\hline FWEIGHT & Thrust Stand Pre-test thrust off-set, lbf $(\mathrm{kN})$ \\
\hline $\mathrm{GCH}_{4}$ & Gaseous Methane \\
\hline $\mathrm{GO} 2$ & Gaseous Oxygen \\
\hline IPP & Innovative Partnership Program \\
\hline ISP & Vacuum Specific Impulse, sec \\
\hline $\mathrm{LCH}_{4}$ & Liquid Methane \\
\hline LEM & Lunar Excursion Module \\
\hline $\mathrm{LN}_{2}$ & Liquid Nitrogen \\
\hline $\mathrm{LO}_{2}$ & Liquid Oxygen \\
\hline LASS & Large Altitude Simulation System \\
\hline LSAM & Lunar Surface Access Module \\
\hline MMH & Monomethyl hydrazine \\
\hline NIST & National Institute of Standards and Technology \\
\hline NTO & Nitrogen tetroxide \\
\hline PCAD & Propulsion and Cryogenics Advanced Development \\
\hline RCE & Reaction Control Engine \\
\hline TS & Test-Stand \\
\hline UDMH & Unsymmetrical Dimethylhydrazine \\
\hline WSTF & White Sands Test Facility \\
\hline
\end{tabular}

\section{References}

${ }^{1}$ Stanly, D., manager, "NASA's Exploration Systems Architecture Study," NASA-TM-2005-214062, 2005.

${ }^{2}$ Trinh, H., "Liquid Methane / Oxygen Injector Study for Potential Future Mars Ascent Engines," AIAA 2000-3119, 36th AIAA/ASME/SAE/ASEE Joint Propulsion Conference and Exhibit, Huntsville, AL, July 17-19, 2000.

${ }^{3}$ Zurbach, S., Thomas, J., Verplancke, C., Vingert, L., Habiballah, M., "LO2/Methane Studies for Fuel Rich Preburner," AIAA 2003-5063, 39th AIAA/ASME/SAE/ASEE Joint Propulsion Conference and Exhibit, Huntsville, AL, July 20-23, 2003. 
${ }^{4}$ Botwin, R., "Flight Performance of the LM Ascent and Descent Propulsion Systems," AIAA-70-673, AIAA 6th Propulsion Joint Specialist Conference, San Diego, CA, June 15-19, 1970.

${ }^{5}$ Huebner, L., Saiyed, N., and Swint, M., "Advanced Development Projects for Constellation from the Next Generation Launch Technology Program Elements," IAC-05-D2.5.08, 56th International Astronautical Congress of the International Astronautical Federation, the International Academy of Astronautics, and the International Institute of Space Law, Fukuoka, Japan, Oct 17-21, 2005.

${ }^{6}$ Robinson, P., Veith, E., and Turpin, A., "Test Results for a Non-Toxic Dual Thrust Reaction Control Engine," AIAA-2005-4457, 41st AIAA/ASME/SAE/ASEE Joint Propulsion Conference and Exhibit, Tucson, AZ, July 10-13, 2005.

${ }^{7}$ Hurlbert, E., Angstadt, T., Villemaratte, M., Collins, J., Allred, J., Mahoney, J., and Peters, T., "870 lbf Reaction Control System Tests using LOX/Ethanol and LOX/Methane at White Sands Test Facility," AIAA-20085247, 44th AIAA/ASME/SAE/ASEE Joint Propulsion Conference and Exhibit, Hartford, CT, July 20-23, 2008.

${ }^{8}$ Melcher, J. and Allred, J., "Liquid Oxygen/Liquid Methane Testing of the RS-18 at NASA White Sands Test Facility," AIAA-2008-4843, 44th AIAA/ASME/SAE/ASEE Joint Propulsion Conference and Exhibit, Hartford, CT, July 20-23, 2008.

${ }^{9}$ U.S. Department of Commerce National Institute of Standards and Technology, "Cryogenic Coriolis Flowmeter Micro Motion Meter Two Inch Serial No. 356600," Test No. 813560, Micro Motion, Boulder, CO, 1998.

${ }^{10}$ Baird, R., "Flowmeter Evaluation for On-Orbit Operations," NASA Technical Memorandum 100 465, Johnson Space Center, Houston, TX, 1988.

${ }^{11}$ Lemmon, E. W., Huber, M. L., and McLindon, M. O., "REFPROP Reference Fluid and Thermodynamic Transport Properties," NIST Standard Reference Database 23, Version 8.0, 2007. 